\title{
Ocular findings in a double-blind study of ivermectin versus diethylcarbamazine versus placebo in the treatment of onchocerciasis
}

\author{
K Y DADZIE, ${ }^{\prime}$ A C BIRD, ${ }^{2} \mathrm{~K}$ AWADZI, ${ }^{3} \mathrm{H}$ SCHULZ-KEY,${ }^{4} \mathrm{H} \mathrm{M}$ GILlES, ${ }^{5}$ \\ AND M A AZIZ \\ From the 'Onchocerciasis Control Programme, PO Box 549, Ouagadougou, Burkina Faso; ${ }^{2}$ Department of \\ Clinical Ophthalmology, Institute of Ophthalmology, Moorfields Eye Hospital, City Road, London; \\ ${ }^{3}$ Onchocerciasis Chemotherapeutic Research Centre, Tamale Hospital, Ghana $;{ }^{4}$ Tropenmedizinisches Institut, \\ Wilhemstrasse 31, 7400, Tubingen 1; 'Department of Tropical Medicine, Liverpool School of Tropical \\ Medicine, Pembroke Place, Liverpool L3 5QA; ${ }^{\circ}$ Merck Sharp and Dohme Research Laboratories, \\ PO Box 2000, Rahway, New Jersey 07065, USA
}

SUMmaRY The effect of ivermectin, a new microfilaricide, was assessed in a double blind trial against diethylcarbamazine citrate (DEC) and placebo. Fifty-nine adult males with moderate to heavy infection with Onchocerca volvulus and with eye involvement were recruited from an area under Onchocerciasis Control Programme (OCP) vector control in Northern Ghana. They were randomly assigned to an eight-day treatment with ivermectin as a single dose of $12 \mathrm{mg}$ on day 1 followed by placebo for the remaining seven days, or DEC, total dose $1.3 \mathrm{~g}$, or placebo, and ophthalmological review was undertaken over a period of one year. DEC acted quickly to eliminate microflariae from the eye and was associated with reactive ocular changes and in a few cases functional deficit. Ivermectin eliminated microfilariae slowly from the anterior chamber of the eye over a period of six months. The ocular inflammatory reaction was minimal and no functional deficit occurred. It is postulated that the observed slow action of ivermectin on the eye may be attributed in part to its inability to cross the blood-aqueous humour barrier because of its molecular size as a macrocyclic lactone causing microfilariae to leave the eye gradually along a newly created gradient. Ivermectin is an effective microfilaricide with minimal ocular adverse effect and could therefore be suitable for widespread application without strict supervision.

Diethylcarbamazine (DEC) $)^{1-6}$ and suramin $^{3-11}$ have been used for over three decades in the treatment of ocular onchocerciasis. When used judiciously under steroid cover, DEC may cause lesions of the anterior segment of the eye to resolve, ${ }^{12-14}$ but no such advantage is thought to occur in respect of posterior segment ocular involvement. ${ }^{5121516}$ Recently it has been shown by fluorescein angiography ${ }^{17}$ that new or increased retinal pigment epithelial and optic nerve disease can occur during treatment of ocular onchocerciasis with DEC and that such disease is associated with functional loss. The eye damage appears to be an exaggerated form of the inflammatory reaction that occurs under natural conditions. These ocular

Correspondence to Dr K Y Dadzie. complications as well as other systemic side effects of therapy have discouraged indiscriminate mass treatment with DEC, and its unrestricted use is not recommended. ${ }^{18}$ There is therefore a need for a safer drug for the treatment of onchocerciasis.

Ivermectin, a macrocyclic lactone, was first reported in $1982^{19}$ to be effective in the treatment of patients lightly infected with onchocerciasis and to cause little or no Mazzotti reaction, a generalised inflammatory reaction following DEC therapy in response to microfilarial death. The efficacy was confirmed in subsequent studies, ${ }^{20-22}$ which also reported ivermectin to be safe to the eye. Recent reports on double blind comparative studies of ivermectin, DEC, and placebo ${ }^{2324}$ have also supported these conclusions. 
This paper reports on further experience with ivermectin in the treatment of ocular onchocerciasis in a double blind study comparing ivermectin, DEC, and placebo in an area subject to vector control under the WHO Onchocerciasis Control Programme (OCP).

\section{Patients and methods}

\section{PATIENT SELECTION}

Fifty-nine otherwise healthy adult males aged between 15 and 50 years with moderate to heavy infection with Onchocerca volvulus and with eye involvement were recruited from 10 villages in the savannah area of northern Ghana where vector control has interrupted the transmission of infection since 1976. All patients were admitted to hospital at the Onchocerciasis Chemotherapeutic Research Centre (OCRC), Tamale Hospital, during drug administration and for several days afterwards. They were readmitted for one or two days for each subsequent examination.

Forty-eight of the 59 patients were retained for ophthalmological analysis. Of the 11 excluded, seven were absent for one of the three- or six-month followup examinations (three who received DEC, three ivermectin, and one placebo), and a further four absconded after the second day of treatment (two in the ivermectin group and two in the placebo group). One patient who took DEC and who was absent at day 28 was retained; his microfilarial counts on day 28 were estimated as the mean between those found at day 14 and at three months. Of the 48 patients retained, 17 received DEC, 15 ivermectin, and 16 placebo.

\section{METHODS}

General examination. A detailed systemic examination was carried out. Values for the parameters used in the quantitation of the Mazzotti reaction ${ }^{25}$ were collected. Haematological and biochemical tests were done as well as routine examination of urine and the examination of membrane filtered urine and blood for microfilariae. These examinations were conducted before treatment started, during the first 10 days of treatment, and at subsequent follow-up visits. Skin snips were taken with a Walser corneoscleral punch from the left outer canthus and from both scapulae, iliac crests, and calves. The microfilarial density for each patient was expressed per mg of skin using the mean of the counts from the four sites on the left. Skin snips were repeated on days 2 , $4,8,14$, and 28 and at $3,6,9$ and 12 months after the start of treatment. Nodulectomy was carried out at one and six months to determine the effect of the drug on the adult worm.
Ophthalmological examination. This was undertaken before treatment began and on the $2 \mathrm{nd}$, 4th, 8th, 14th, and 28th days and 3,6, and 12 months after the start of treatment. This included a visual acuity test using the illiterate E chart at $6 \mathrm{~m}$ distance for each eye separately and without correction for refractive error as well as a visual field test using $1 \mathrm{~m}$ Bjerrum tangent screen with a $2 \mathrm{~mm}$ white target in daylight at 1 metre distance. Slit-lamp examination was conducted after head down positioning of patients for at least two minutes to facilitate and standardise counting of microfilariae in the anterior chamber. Microfilariae, both dead and alive, and onchocercal punctate keratitis in the cornea were counted. The intraocular pressure was measured after the examination of the anterior segment of the eye was completed. The fundus was examined by both direct and indirect ophthalmoscopy after pupil dilatation. Fundus photography and fluorescein angiography were undertaken with a Topcon TRC fundus camera initially and later a Kowa RC2.

Drug administration. Twenty patients received DEC in a dose of $50 \mathrm{mg}$ each morning for two days and then $100 \mathrm{mg}$ twice daily for a further six days; 20 received ivermectin in a single dose of $12 \mathrm{mg}$ on the morning of the first day and placebo capsules thereafter; and 19 received matching placebo capsules containing $185 \mathrm{mg}$ corn starch (STA-RX L500) per capsule for the duration of therapy. The drugs, which were formulated in identical capsules and precoded, were allocated randomly to patients on arrival in the hospital. An elaborate check system was conducted to ensure correct drug administration and complete ingestion.

Statistical analysis. Non-parametric significance tests have been applied. The Kruskal-Wallis one-way ANOVA was used to compare all three treatment groups and the Mann-Whitney U test to compare the two treatment groups on each examination day. Within each group the post-treatment data were compared with baseline data by the Wilcoxon matched pairs, signed-ranks test. The study code was broken after the six months follow-up examination.

Table 1 Pretreatment general features of patients in the three treatment groups

\begin{tabular}{llll}
\hline Feature & \multicolumn{2}{l}{ Treatment group } & \\
\cline { 2 - 4 } & $\begin{array}{l}\text { DEC } \\
(n=17)\end{array}$ & $\begin{array}{l}\text { Invermectin } \\
(n=15)\end{array}$ & $\begin{array}{l}\text { Placebo } \\
(n=16)\end{array}$ \\
\hline Age & $33(18-45)$ & $32 \cdot 1(17-50)$ & $30 \cdot 1(15-47)$ \\
Weight (kg) & $56 \cdot 7(44-65)$ & $57 \cdot 0(42-67)$ & $55 \cdot 3(46-69 \cdot 6)$ \\
Skin atrophy* & 9 & 8 & 4 \\
Nodules* $^{*}$ & 16 & 14 & 13 \\
\hline
\end{tabular}

${ }^{*}$ Number of cases with the onchocercal lesion. 
Table 2 Important pretreatment ocular lesions and changes occurring after treatment

\begin{tabular}{|c|c|c|c|c|c|c|c|c|c|c|c|}
\hline & \multicolumn{8}{|c|}{ Pretreatment ocular status } & \multicolumn{3}{|c|}{ Newlesions } \\
\hline & \multicolumn{3}{|c|}{ Visual acuity } & \multirow{2}{*}{$\begin{array}{l}\text { Visual } \\
\text { field } \\
\text { defect }\end{array}$} & \multicolumn{2}{|c|}{$\begin{array}{l}\text { Ophthalmoscopy/ } \\
\text { fundus photo }\end{array}$} & \multicolumn{2}{|c|}{$\begin{array}{l}\text { Fluorescein } \\
\text { angiogrphy }\end{array}$} & \multirow[t]{2}{*}{$\begin{array}{l}\text { Field } \\
\text { loss }\end{array}$} & \multirow[t]{2}{*}{$\begin{array}{l}\text { Disc } \\
\text { leak }\end{array}$} & \multirow{2}{*}{$\begin{array}{l}\text { RPE } \\
\text { abnor- } \\
\text { mality }\end{array}$} \\
\hline & $A$ & $\boldsymbol{B}$ & $C$ & & $\begin{array}{l}\text { Disc } \\
\text { lesions }\end{array}$ & $\begin{array}{l}\text { Retinal } \\
\text { lesions }\end{array}$ & $\begin{array}{l}\text { Disc } \\
\text { leak }\end{array}$ & $\begin{array}{l}\text { RPE } \\
\text { abnor- } \\
\text { mality }\end{array}$ & & & \\
\hline DEC citrate $(n=17)$ & 13 & 3 & 1 & 10 & 11 & 8 & 13 & 8 & 2 & 2 & 4 \\
\hline Ivermectin $(n=15)$ & 13 & 2 & 0 & 8 & 7 & 8 & 10 & 5 & 0 & 2 & 2 \\
\hline Placebo $(n=16)$ & 13 & 0 & 3 & 8 & 9 & 4 & 13 & 8 & 0 & 0 & 2 \\
\hline
\end{tabular}

Figures indicate number of cases.

Visual acuity of worst eye: $A=6 / 4-6 / 9$. $B=6 / 12-6 / 24 . C=\geq 6 / 36$.

$\mathrm{RPE}=$ retinal pigment epithelium.

\section{Results}

\section{PRETREATMENT}

General. The patients in the three treatment groups were similar with regard to age, weight, symptomatology, and systemic clinical findings (Table 1). The means of the skin microfilarial counts with $95 \%$ confidence limits in patients treated with DEC, ivermectin, and placebo were 112 (81-154), 154 (107-223), and 138 (104-184) respectively.

\section{Ocular}

Visual function. The visual acuity in all but nine patients was $6 / 9$ or better with each eye. The reduced visual acuities were not attributed to onchocerciasis in any patient.

More than half the patients had abnormalities of visual fields which were predominantly constriction or arcuate defects resulting from onchocercal optic nerve disease, or corresponded to choroidoretinal disease. The frequency of occurrence of normal and abnormal visual acuity or peripheral visual fields was similar in the three treatment groups (Table 2).

Ocular parasites. Forty-four of 48 patients, 15 in the DEC group, 14 in the ivermectin group, and 15 in the placebo group, had ocular microfilariae. Microfilariae were found predominantly in the anterior chamber of the eye. Patients who took DEC tended to have lowest counts (Fig. 1), but there was no statistically significant difference between the three treatment groups $(p=0 \cdot 16$, Kruskal-Wallis test $)$. Microfilariae were found in small numbers (fewer than 10) in the corneae of 11 patients - two in the $\mathrm{DEC}$, six in the ivermectin, and three in the placebo group. Punctuate keratitis occurred in two patients each in the DEC and ivermectin groups. There were no statistically significant differences among the three groups.
Fig. 1 Pretreatment distribution of microfilariae in the anterior chamber of the eyes in patients treated with ivermectin, $D E C$, or placebo. $\square \backslash=$ ivermectin $(n=15)$. $\triangle \nabla=D E C(n=17)$. $\mathbb{Z Z}=$ placebo $(n=16) . M F=$ microfilariae. $A / C=$ anterior chamber.

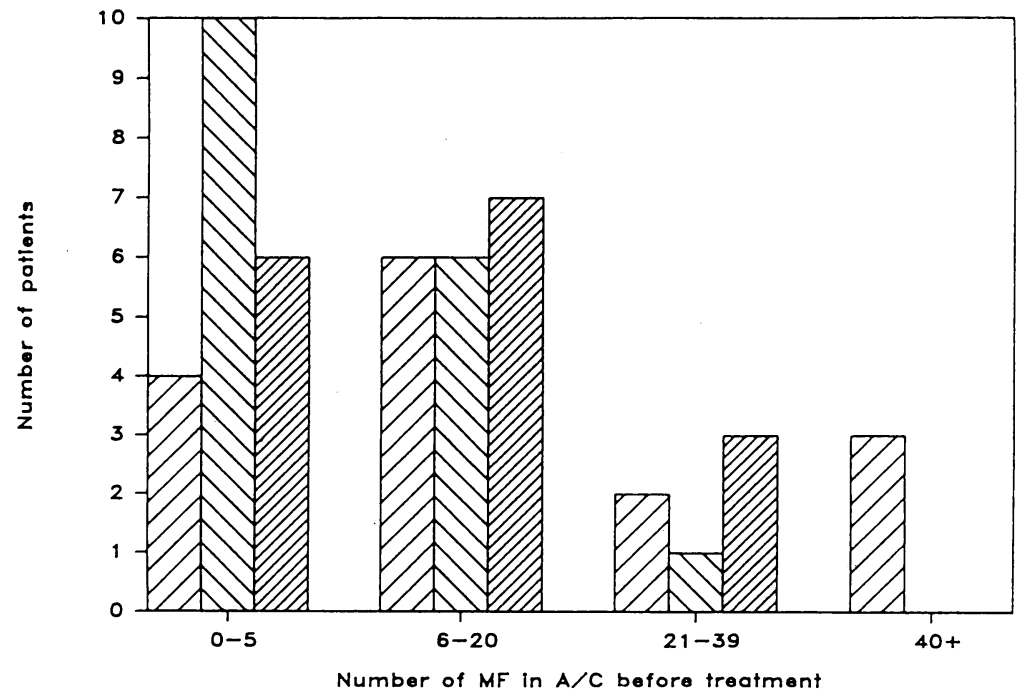




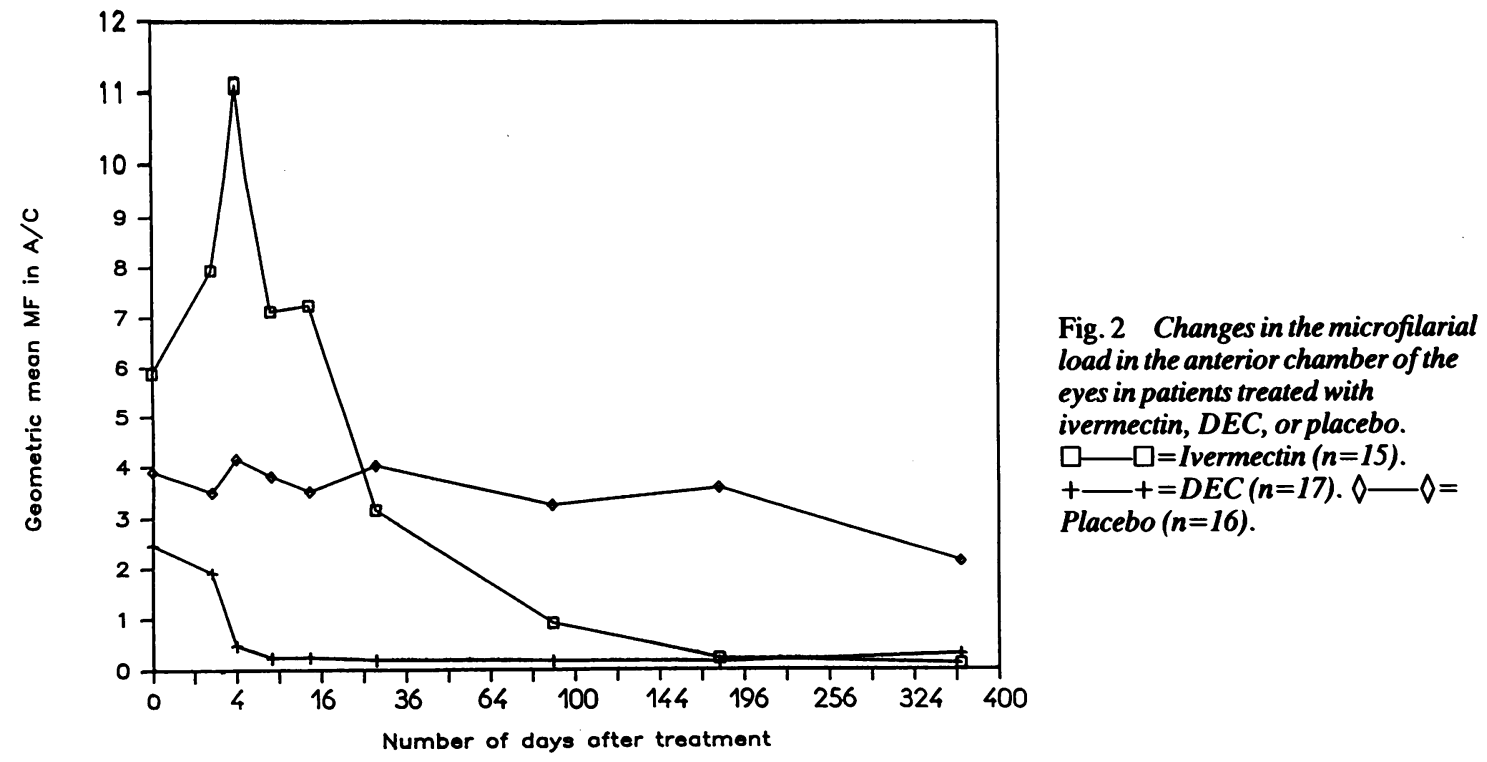

Ocular fundus. Nearly $60 \%$ of the patients had onchocercal fundus lesions (Table 2). Mild atrophy of the temporal retinal pigment epithelium was found frequently, but occasional severe forms extended nasally towards the optic disc. Severe choroidoretinal scarring was found in one patient each in the DEC and ivermectin groups. Chronic low grade optic neuritis, frank as well as in the early stage of optic atrophy, was found at about the same frequency in each group. With fluorescein angiography still earlier grades of these fundus lesions were detected. These were distributed in a similar frequency among the treatment groups.

\section{RESPONSE TO TREATMENT \\ General}

Systemic reactions. Headache, joint pains, muscle aches, and cardiovascular reactions were found with equal overall severity in both treatment groups. However, itching, node pain and tenderness, tachypnoea, and rash were more severe in DEC than in ivermectin treated patients. Fever was more prominent with ivermectin treatment than with DEC. Acute febrile polyarthritis involving the knees, ankles, elbows, and small joints of the hands and feet, which occurs classically several days after initiation of therapy, was observed in five patients treated with DEC but in none of those treated with ivermectin.

Skin microfilariae. Both DEC and ivermectin treated groups showed a similarly significant decrease in the mean microfilarial density compared with the placebo treated group, with the lowest mean level of 1.3 microfilariae per mg of skin at day 8 for DEC and 0.9 at day 14 and 28 for ivermectin. Both groups showed a slight rise at six months, but at 9 and 12 months the DEC treated group had reached a significantly higher level than the ivermectin group.

Adult worm. No macrofilaricidal effect was observed on adult worms removed at both one and six months with either DEC or ivermectin. A remarkably high number of degenerate microfilariae were seen in gravid worms taken at six months from patients treated with ivermectin.

\section{Ocular}

Changes in ocular parasite load. DEC caused rapid elimination of microfilariae from the anterior chamber, reaching near zero level by day 8 , and remaining at this level with only minor fluctuation over the period of one year (Fig. 2). This reduction, compared with that in the placebo treated group, is

Table 3 Statistical significance of observed differences between treatment groups in microfilarial counts in the anterior chamber (Mann-Whitney U test)

\begin{tabular}{|c|c|c|c|c|c|c|c|c|c|}
\hline Day of treatment & Day 0 & Day 2 & Day 4 & Day 8 & Day 14 & Day 28 & Month 3 & Month 6 & Month 12 \\
\hline $\begin{array}{l}\text { DEC vs ivermectin } \\
\text { DEC vs placebo } \\
\text { Ivermectin vs placebo }\end{array}$ & $\begin{array}{l}\text { NS } \\
\text { NS } \\
\text { NS }\end{array}$ & $\begin{array}{l}<0.05 \\
\text { NS } \\
\text { NS }\end{array}$ & $\begin{array}{l}<0.001 \\
<0.001 \\
<0.05\end{array}$ & $\begin{array}{l}<0.001 \\
<0.001 \\
\text { NS }\end{array}$ & $\begin{array}{l}<0 \cdot 001 \\
<0 \cdot 001 \\
\text { NS }\end{array}$ & $\begin{array}{l}<0.001 \\
<0.001 \\
\text { NS }\end{array}$ & $\begin{array}{l}\text { NS } \\
<0.001 \\
<0.05\end{array}$ & $\begin{array}{l}\text { NS } \\
<0.001 \\
<0.001\end{array}$ & $\begin{array}{l}\text { NS } \\
<0.01 \\
<0.001\end{array}$ \\
\hline
\end{tabular}


Fig. 3 Changes in the corneal microfilarial load in patients treated with ivermectin, DEC, or placebo. $\square-\square=$ Ivermectin $(n=15)$. $+-+=D E C(n=17) . \diamond-\diamond=$ Placebo $(n=16)$.

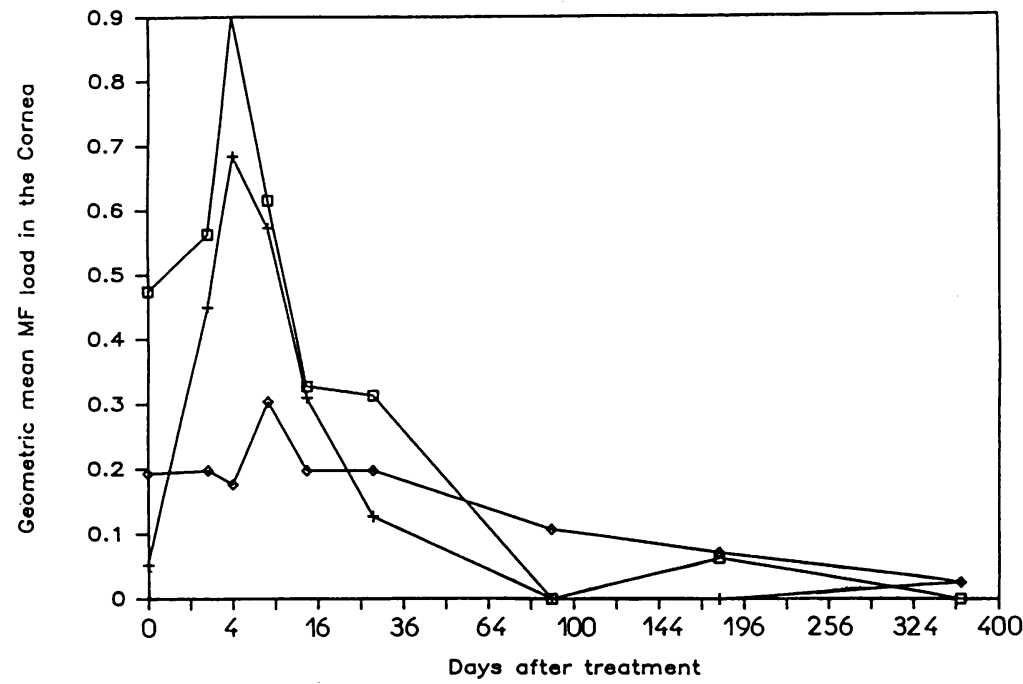

significant from day 4 onwards (Table 3 ). With ivermectin a significant increase of the microfilarial load from the pretreatment level occurred, with a peak at day $4(p<0.001$, Wilcoxon signed-ranks test), followed by a gradual decrease to significantly lower than that for placebo at three months and to near zero level (similar to DEC) by six months. The placebo treated group showed no rapid change in the microfilarial load, though at one year it appeared reduced.

Both the DEC and ivermectin groups increased from the baseline corneal microfilarial count to a peak on day 4; the increase caused by DEC was significant on days 2,4 , and $8(\mathrm{p}<0.01)$ (Fig. 3$)$. Compared with placebo, both DEC and ivermectin increased the corneal microfilarial load significantly on day $4(p<0.05)$. Increase in onchoceral punctate keratitis occurred mainly with DEC and was significant on days $4(p<0.01), 8(p<0.01)$, and $14(p<0.05)$ (Wilcoxon signed-ranks test), but was significantly increased compared with placebo only on day 4 ( $p<0.01 ;$ Mann-Whitney U test.

Inflammatory signs. Mild or moderate limbitis occurred more frequently in the DEC group than in the ivermectin group; a moderate limbitis was observed in one patient only who took ivermectin (Table 4). An increase in fluffy corneal opacities was seen only in patients treated with DEC (Fig. 4). In the placebo group only occasional limbal injection was observed. Mild flare was observed at a similar frequency in both the DEC and ivermectin groups and less frequently in the placebo group. One case of mild to moderate iridocyclitis occurred in each of the ivermectin and placebo groups but none in the DEC group.

Fundus changes. Four patients with optic disc changes were observed with fluorescein angiography, of whom two had received DEC treatment. One of these showed increasing disc hyperfluorescence from day 2 to 28 and fresh pigment epithelial lesions. ${ }^{17}$ This patient lost fields bilaterally and progressively from day 4 , to stabilise as bilateral contracted fields by day 14. The other patient showed an increasing disc hyperfluorescence from day 2 to 8 without pigment epithelial change but with accompanying left eye field loss on day 2 , followed by the right on day 4 , and progressing gradually until day 28 . The two other

Table 4 Comparison of inflammatory signs

\begin{tabular}{|c|c|c|c|c|c|c|c|c|c|c|c|c|c|c|c|c|c|c|c|c|c|}
\hline \multirow[t]{2}{*}{ Days of treatment } & \multicolumn{7}{|c|}{$D E C(n=17)$} & \multicolumn{7}{|c|}{ Ivermectin $(n=15)$} & \multicolumn{7}{|c|}{$\operatorname{Placebo}(n=16)$} \\
\hline & 2 & 4 & 8 & 14 & 28 & 90 & 180 & 2 & 4 & 8 & 14 & 28 & 90 & 180 & 2 & 4 & 8 & 14 & 28 & 90 & 180 \\
\hline $\begin{array}{l}\text { Limbal injection } \\
\text { Limbitis: mild } \\
\text { moderate }\end{array}$ & $\begin{array}{l}0 \\
7 \\
3\end{array}$ & $\begin{array}{l}0 \\
8 \\
4\end{array}$ & $\begin{array}{l}0 \\
4 \\
0\end{array}$ & $\begin{array}{l}\mathbf{0} \\
\mathbf{0} \\
\mathbf{0}\end{array}$ & $\begin{array}{l}\mathbf{0} \\
\mathbf{0} \\
\mathbf{0}\end{array}$ & $\begin{array}{l}\mathbf{0} \\
\mathbf{0} \\
\mathbf{0}\end{array}$ & $\begin{array}{l}\mathbf{0} \\
\mathbf{0} \\
\mathbf{0}\end{array}$ & $\begin{array}{l}\mathbf{0} \\
3 \\
0\end{array}$ & $\begin{array}{l}0 \\
0 \\
1\end{array}$ & $\begin{array}{l}0 \\
1 \\
0\end{array}$ & $\begin{array}{l}\mathbf{0} \\
\mathbf{0} \\
\mathbf{0}\end{array}$ & $\begin{array}{l}\mathbf{0} \\
\mathbf{0} \\
\mathbf{0}\end{array}$ & $\begin{array}{l}\mathbf{0} \\
\mathbf{0} \\
\mathbf{0}\end{array}$ & $\begin{array}{l}\mathbf{0} \\
\mathbf{0} \\
\mathbf{0}\end{array}$ & $\begin{array}{l}1 \\
0 \\
0\end{array}$ & $\begin{array}{l}\mathbf{0} \\
\mathbf{0} \\
\mathbf{0}\end{array}$ & $\begin{array}{l}2 \\
0 \\
0\end{array}$ & $\begin{array}{l}0 \\
0 \\
0\end{array}$ & $\begin{array}{l}\mathbf{0} \\
\mathbf{0} \\
\mathbf{0}\end{array}$ & $\begin{array}{l}\mathbf{0} \\
\mathbf{0} \\
\mathbf{0}\end{array}$ & $\begin{array}{l}\mathbf{0} \\
0 \\
0\end{array}$ \\
\hline $\begin{array}{l}\text { Flare } \\
\text { Iridocyclitis: mild } \\
\text { moderate }\end{array}$ & $\begin{array}{l}3 \\
0 \\
0\end{array}$ & $\begin{array}{l}3 \\
0 \\
0\end{array}$ & $\begin{array}{l}\mathbf{0} \\
\mathbf{0} \\
\mathbf{0}\end{array}$ & $\begin{array}{l}1 \\
0 \\
0\end{array}$ & $\begin{array}{l}2 \\
0 \\
0\end{array}$ & $\begin{array}{l}1 \\
0 \\
0\end{array}$ & $\begin{array}{l}\mathbf{0} \\
\mathbf{0} \\
\mathbf{0}\end{array}$ & $\begin{array}{l}4 \\
0 \\
1\end{array}$ & $\begin{array}{l}2 \\
1 \\
0\end{array}$ & $\begin{array}{l}0 \\
1 \\
0\end{array}$ & $\begin{array}{l}0 \\
1 \\
0\end{array}$ & $\begin{array}{l}1 \\
0 \\
0\end{array}$ & $\begin{array}{l}\mathbf{0} \\
\mathbf{0} \\
\mathbf{0}\end{array}$ & $\begin{array}{l}0 \\
0 \\
0\end{array}$ & $\begin{array}{l}0 \\
0 \\
0\end{array}$ & $\begin{array}{l}1 \\
0 \\
0\end{array}$ & $\begin{array}{l}1 \\
0 \\
0\end{array}$ & $\begin{array}{l}\mathbf{1} \\
\mathbf{0} \\
\mathbf{0}\end{array}$ & $\begin{array}{l}0 \\
0 \\
1\end{array}$ & $\begin{array}{l}0 \\
1 \\
0\end{array}$ & $\begin{array}{l}0 \\
1 \\
0\end{array}$ \\
\hline
\end{tabular}

NB: No inflammatory sign was observed at 1 year follow-up. 


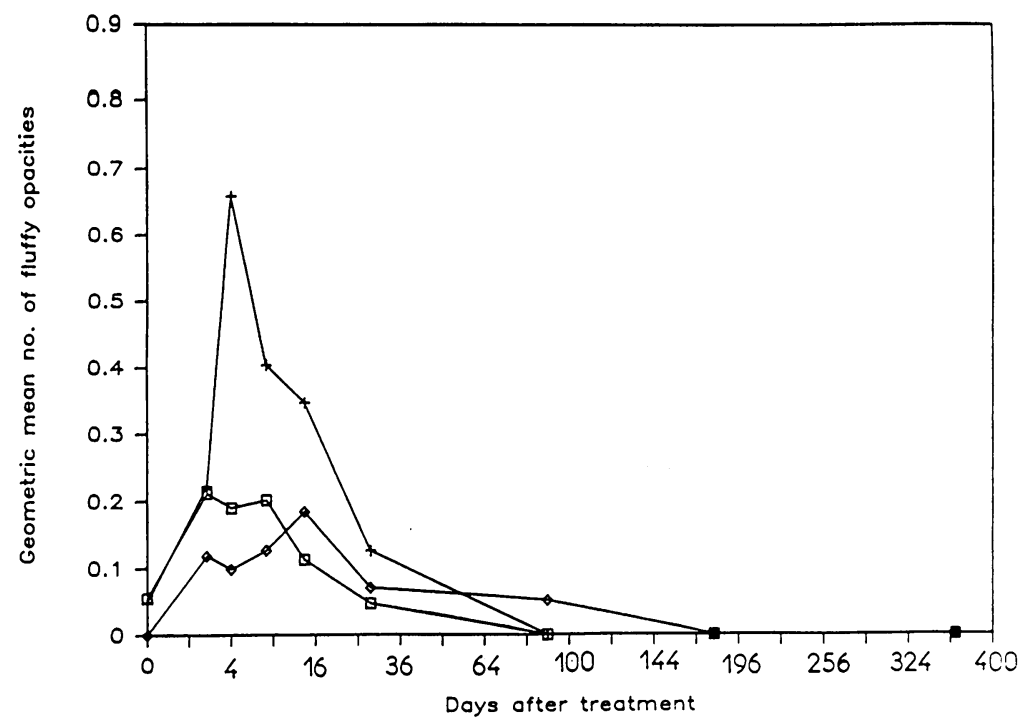

Fig. 4 Changes in the punctate keratitis (fluffy opacities) load in patients treated with ivermectin, $D E C$, or placebo. $\square-\square=$ Ivermectin $(n=15)$. $+-+=D E C$ $(n=17) . \diamond-\downarrow=$ Placebo $(n=16)$.

patients who had received ivermectin showed increased disc hyperfluorescence from day 2 to 28 ; however, there was no associated visual functional deficit. Optic disc hyperfluorescence that existed initially in six patients who took DEC, seven who took ivermectin, and three who took placebo resolved by one year. New minor pigment epithelial changes were visible at the one-year follow-up in four patients who received DEC, two who took ivermectin, and two who received placebo.

Other ocular changes. Changes in intraocular pressures in the course of the study did not show any definite pattern. No significant changes in the visual acuities were encountered. No other pathological changes were observed in the course of the study.

\section{Discussion}

The effect of a microfilaricide may be observed and quantified by observing the death or the elimination of microfilariae from the anterior segment of the eye and the tissue reaction to dead microfilariae.

In this study the evidence for the elimination of microfilariae from the anterior segment of the eye by both $\mathrm{DEC}$ and ivermectin is demonstrated. Despite the low counts of corneal microfilariae initially, which is a normal finding in patients in an area under vector control ${ }^{26}$ the mobilisation of microfilariae into the cornea ${ }^{12}$ during the first week of treatment occurred in both the DEC and ivermectin treated groups, the effect with DEC being the greater. However, only DEC caused a significant increase in onchocercal punctate keratitis. This phenomenon has also been observed in similar trials. ${ }^{2223} \mathrm{As}$ in our previous open study, ${ }^{22}$ the most striking finding was the mobilisation of microfilariae into the anterior chamber by ivermectin to a peak on day 4 which was a significant increase from baseline, followed by elimination to zero level by six months, while DEC promptly eliminated microfilariae to near zero level by day 8 .

Although it is believed that the antiparasitic effect of ivermectin may result from its action in the mediation of neurotransmission by $\gamma$-aminobutyric acid, ${ }^{27}$ and although ivermectin has been shown to kill Onchocera lienalis in vitro ${ }^{28}$ the precise mode of action of ivermectin in human ocular onchocerciasis is unknown, and several factors may have a contributory role. As a macrocyclic lactone, it is possible that ivermectin cannot cross the blood-aqueous humour barrier to enter the anterior chamber of the eye and exert direct action on the microfilariae. Ivermectin may conceivably act by eliminating the source of microfilariae migrating into the eye from surrounding skin and orbital tissue, thus reversing the microfilarial concentration gradient. Microfilariae may then leave the anterior chamber along this gradient, possibly along the same route by which they entered, or they might die naturally. This lack of microfilaricidal effect of ivermectin in the eye might account for the paucity of ocular inflammatory reaction. By contrast, DEC has been shown to enter the anterior chamber of the eye in therapeutic concentrations. ${ }^{29}$ However, it is believed that DEC does not cause microfilarial death directly, but causes dissolution of the outer protective layer, which is followed by killing of the microfilaria by cellular immune mechanisms. Thus DEC causes death of microfilariae only in vivo but not in vitro. It has been suggested that in the anterior chamber of the eye, where cellular defence mechanisms are absent, DEC can only unmask microfilariae. This led to the 
suggestion that DEC in therapeutic doses mobilises vulnerable microfilariae from the anterior chamber either into ocular tissues or out of the eye where they are killed..$^{3031}$ It is well recognised that one of the properties of DEC is the mobilisation of microfilariae. ${ }^{12}$

The postulated actions of the two drugs may explain the difference in time taken to eliminate microfilariae from the anterior chamber of the eye as well as differences in ocular tissue reaction in the form of inflammation. Limbitis, which can be used to quantify the severity of host reaction to a microfilaricide, ${ }^{32}$ occurred in the majority of patients treated with DEC but rarely in those treated with ivermectin. DEC caused optic nerve and pigment epithelial changes with functional deficit; although ivermectin caused papillitis, this was mild and was not associated with any defect in function. In similar studies $^{232}$ no changes at the posterior segment of the eye were observed in ivermectin treated patients.

Although the incidence of eye changes associated with DEC treatment in this study is quite considerable, it is still less than that reported by Bird et al. ${ }^{17}$ in their study of 21 patients who were observed for two weeks in southern Sudan. Factors that may contribute to this difference may be: (1) the intensity of infection of the patients, which is lower in this study; (2) possible differences in the pattern of disease in the two different subregions; and (3) the possibility of changing host reaction in association with the interruption of transmission of infection. The absence of transmission of infection has been shown to lead to a decrease in the microfilarial load in the eye ${ }^{26}$ and this is reflected in the decreased microfilarial load of the anterior chambers and the resolution of papillitis in the placebo group after one year, as diagnosed by fluorescein angiography.

This double blind study in patients living in an area subject to OCP vector control shows that ivermectin exerts a slow microfilaricidal effect on the eye, but, unlike DEC, does not produce any serious inflammatory reaction likely to cause functional deficit. These observations accord with those of our previous study. ${ }^{22}$ In the light of similar conclusions drawn from studies undertaken where transmission of $O$. volvulus continues unabated ${ }^{23}{ }^{24}$ it would appear that treatment with ivermectin is not associated with serious ophthalmological adverse effect and may be suitable for mass treatment. Further studies in patients with very heavy ocular infection are clearly needed.

\footnotetext{
We are grateful to Merck Sharp and Dohme Research Laboratories for the supply of ivermectin and for financial support, to Dr Samba, Programme Director, Onchocerciasis Control Programme, for his keen interest in and support for the study and to $\mathrm{J}$ Remme for his invaluable statistical advice and support.
}

\section{References}

1 Weyts EJ. Ocular manifestations in onchocerciasis. Doc Med Geogr 1956; 8: 29-38.

2 Rodger FC. Comparison of the effect upon onchocerciasis of five drugs and selection of the one best able to prevent ocular complications. Trans R Soc Trop Med Hyg 1958; 52: 462-7.

3 Quere MA, Lariviere M, Razafinato R. Les complications oculaires de l'onchocercose: problème du prognostic visuel chez les sujets traités. Bull Soc Med Afr Noire Fr 1965; 10: 19-21.

4 Toufic N. Les difficultés thérapeutiques de l'onchocercose oculaire. Arch Ophthalmol (Paris) 1969; 29: 777-84.

5 Vedy J, Sirol J. A propos d'une papillite onchocerquienne. Med Trop (Mars) 1971; 31: 559-64.

6 Rolland A. Le traitement des onchocerquiens présentant des troubles oculaires. WHO mimeographed document 1973; WHO/ONCHO/73.104: 1-5.

7 Toulant PF, Boithias R. Les lésions oculaires de l'onchocercose africaine. Med Trop (Mars) 1954; 14: 191-9.

8 D'Haussy R, Ritt JM, Lagraulet J. Contribution à l'étude des lésions du fond d'oeil dans l'onchocercose. Med Trop (Mars) 1958; 18: 340-67.

9 Budden FH. Onchocerciasis therapy. Trans $R$ Soc Trop Med Hyg 1959; 53: 118-9.

10 Degabriel J, Lucot J, Chovet $M$. Onchocercose: critères d'évaluation des résultats d'une campagne thérapeutique en milieu rural. Med Trop (Mars) 1970; 30: 795-800.

11 Rodger FC. Selective preventive treatment of onchocerciasis. Isr J Med Sci 1972; 8: 1163-5.

12 Anderson J, Fuglsang H, Marshall TF de C. Effects of diethylcarbamazine on ocular onchocerciasis. Tropenmed Parasitol 1976; 27: 263-78.

13 Duke BOL, Thylefors B, Rougemont A. Current views on the treatment of onchocerciasis with diethylcarbamazine citrate and suramin 1981. WHO/ONCHO/81.156.

14 Rolland A, Thylefors B. Les bases du traitement et de la prévention de l'onchocercose oculaire. Rev Int Trach Pathol Ocul Trop Subtrop Sante Publique 1982; 4: 31.

15 Anderson J, Fuglsang H, Marshall TF de C. Effects of suramin on ocular onchocerciasis. Tropenmed Parasitol 1976; 27: 279-93.

16 Thylefors B, Rolland A. The risk of optic atrophy following suramin treatment of ocular onchocerciasis. Bull WHO 1979; 57: 479-80.

17 Bird AC, El-Sheikh H, Anderson J, Fugslang H. Changes in visual function and in the posterior segment of the eye during treatment of onchocerciasis with diethylcarbamazine citrate. $\mathrm{BrJ}$ Ophthalmol 1980; 64: 191-200.

18 Pathogenesis and treatment of ocular onchocerciasis. Report of the 8th meeting of the WHO Scientific Working Group on Filariasis in collaboration with the Programme for the Prevention of Blindness 1982; TDR/FIL/SWG8 2.3.

19 Aziz MA, Diallo S, Diop IM, Lariviere M, Porta M. Efficacy and tolerance of ivermectin in human onchocerciasis. Lancet. 1982; ii: $171-3$.

20 Coulaud JP, Lariviere M, Cervais MC, et al. Traitement de l'onchocercose humaine par l'ivermectine. Bull Soc Path of Exot Filiales 1983; 76: 681-8.

21 Coulaud JP, Lariviere M, Aziz MA, et al. Ivermectin in onchocerciasis. Lancet 1984; ii: 526-7.

22 Awadzi K, Dadzie KY, Schulz-Key H, Haddock DRW, Gilles HM, Aziz MA. The chemotherapy of onchocerciasis X. An assessment of four single dose treatment regimes of MK-933 (ivermectin) in human onchocerciasis. Ann Trop Med Parasitol 1985; 79: 63-78.

23 Greene BM, Taylor HR, Cupp EW, et al. Comparison of ivermectin and diethylcarbamazine in the treatment of onchocerciasis. N Engl J Med 1985; 313: 133-8.

24 Lariviere M, Vingtain P, Aziz M, et al. Double blind study of ivermectin and diethylcarbamazine in African onchocerciasis patients with ocular involvement. Lancet 1985; ii: 174-7. 


\section{Findings in a study of ivermectin versus diethylcarbamazine versus placebo in the treatment of onchocerciasis 85}

25 Awadzi K. The chemotherapy of onchocerciasis II. Quantitation of the clinical reaction to the microfilaricides. Ann Trop Med Parasitol 1980; 74: 190-7.

26 Dadzie KY, Rolland A, Thylefors B. The evolution of ocular onchocerciasis in the Volta River Basin Area over a period of five years of vector control. Tropenmed Parasitol 1984; 6: 479-566.

27 Campbell WC, Fisher MH, Stapley EO, Albers-Schonberg G, Jacob TA. Ivermectin: A potent new antiparasitic agent. Science 1983; 121: 823-8.

28 Devaney E, Howells RE. The microfilaricidal activity of ivermectin in vitro and in vivo. Tropenmed Parasitol 1984; 35: 44-9.

29 Lazar M, Lieberman TW, Furman M, Leopold IH. Ocular penetration of hetrazan in rabbits. Am J Ophthalmol 1968; 66: 215-20.

30 Duke BOL, Moore PJ, Vincelette J. The population dynamics of Onchocerca volvulus. microfilariae during treatment with suramin and diethylcarbamazine. Tropenmed Parasitol 1976; 27: 133-44.

31 Hawking F. Diethylcarbamazine. A review of the literature with special reference to its pharmacodynamics, toxicity and use in the therapy of onchocerciasis and other filarial infections. 1978. WHO/ONCHO/78.142.

32 Jones BR, Anderson J, Fuglsang H. Effects of various concentrations of diethylcarbamazine citrate applied as eye drops in ocular onchocerciasis, and the possibilities of improved therapy from continuous non-pulsed delivery. Br J Ophthalmol 1978; 63: 428-39. 